\title{
Correction to: a new Rhodococcus aetherivorans strain isolated from lubricant-contaminated soil as a prospective phenol-biodegrading agent
}

\author{
Taisiya Nogina ${ }^{1}$ - Marina Fomina ${ }^{1}$ - Tatiana Dumanskaya ${ }^{1} \cdot$ Liubov Zelena $^{1}$ - Lyudmila Khomenko ${ }^{1}$. \\ Sergey Mikhalovsky ${ }^{2,3} \cdot$ Valentin Podgorskyi $^{1}$ - Geoffrey Michael Gadd ${ }^{4,5}$
}

Published online: 3 March 2020

(C) Springer-Verlag GmbH Germany, part of Springer Nature 2020

\section{Correction to: Appl Microbiol Biotechnol}

https://doi.org/10.1007/s00253-020-10385-6

The published online version contains mistake in Table 3 . The needed corrections were not done during typesetting. The correct Table 3 is given below.

The online version of the original article can be found at https://doi.org/ $10.1007 / \mathrm{s} 00253-020-10385-6$

Geoffrey Michael Gadd

g.m.gadd@dundee.ac.uk

Taisiya Nogina

tnogina@ukr.net

Marina Fomina

M.Fomina@ukr.net

Tatiana Dumanskaya

dumanska@imv.kiev.ua

Liubov Zelena

zelenalyubov@gmail.com

Lyudmila Khomenko

homenkolud@ukr.net

Sergey Mikhalovsky

sergeymikhalovsky@gmail.com
Valentin Podgorskyi

podgorsky@serv.imv.kiev.ua

Zabolotny Institute of Microbiology and Virology of National, Academy of Sciences of Ukraine, Zabolotny str., 154, Kyiv 03143 , Ukraine

2 ANAMAD Ltd, Sussex Innovation Centre, Science Park Square, Brighton, Falmer BN1 9SB, UK

3 Chuiko Institute of Surface Chemistry, 17, General Naumov Street, Kyiv 03164, Ukraine

4 Geomicrobiology Group, School of Life Sciences, University of Dundee, Dundee, Scotland DD1 5EH, UK

State Key Laboratory of Heavy Oil Processing, Beijing Key Laboratory of Oil and Gas Pollution Control, College of Chemical Engineering and Environment, China University of Petroleum, Beijing 102249, China 


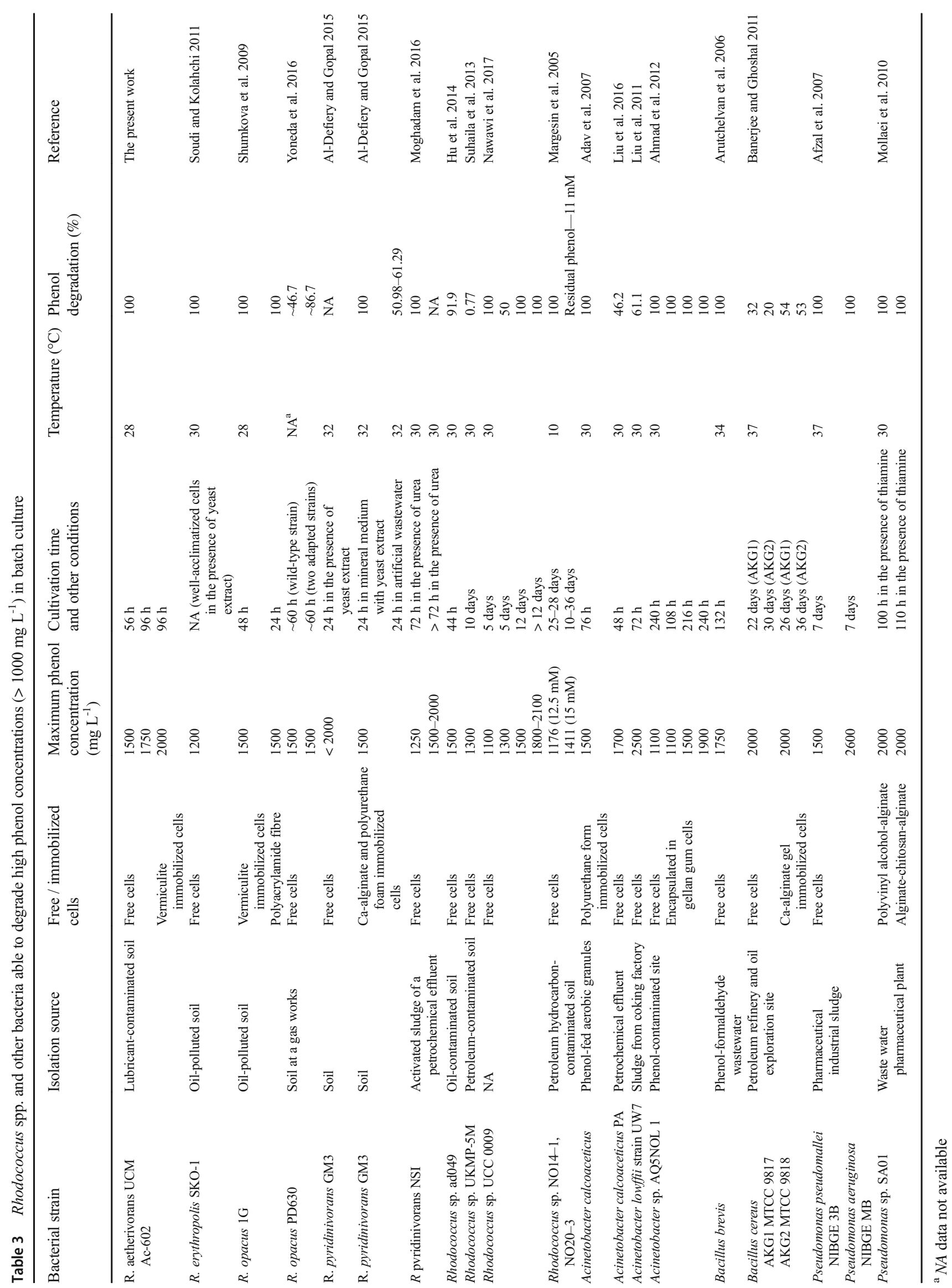

